(95\%CI 0.3-25.6) for OA versus MIS, respectively $(\mathrm{p}=0.757)$ (figure 1). Median OS was 23 months (95\%CI 15.4-30.6) versus 22 months (95\%CI 7.8-37.3) for OA versus MIS, respectively $(p=0.696)$ (figure 2 ). Multivariate analysis demonstrated that the presence of involved surgical margins was the only factor with significant impact on DFS, while surgical approach, grading, metastatic pelvic lymph nodes and adjuvant chemotherapy did not impact DFS.

Abstract 1088 Table 1 Comparison of characteristics of the two groups.

\begin{tabular}{|c|c|c|c|}
\hline Variable & $\begin{array}{l}\text { Open, } \mathrm{N}=48(\% \text {, } \\
\text { range })\end{array}$ & $\begin{array}{l}\text { MIPE, } \mathrm{N}=35(\%, \\
\text { range) }\end{array}$ & $\begin{array}{l}\mathrm{p} \text { - } \\
\text { value }\end{array}$ \\
\hline Median age, years & $49(29-84)$ & $63(38-82)$ & 0.009 \\
\hline Median BMI, kg/m² & $24(13.8-39.5)$ & $26(18.8-53.9)$ & 0.041 \\
\hline $\begin{array}{l}\text { Time from diagnosis to pelvic } \\
\text { exenteration, months }\end{array}$ & $15(4-282)$ & $29(1-288)$ & 0.157 \\
\hline Primary site of disease & $39(81.3)$ & $17(48.6)$ & 0.032 \\
\hline Cervical cancer & $6(12.5)$ & $12(34.3)$ & \\
\hline Endometrial cancer & $2(4.2)$ & $4(11.4)$ & \\
\hline Vaginal cancer & 0 & $1(2.9)$ & \\
\hline Vulvar & $1(2.1)$ & $1(2.9)$ & \\
\hline \multicolumn{4}{|l|}{ Urothelial cancer } \\
\hline Grading & $4(8.3)$ & $4(11.4)$ & 0.398 \\
\hline G1 & 19 (39.6) & $14(40.0)$ & \\
\hline G2 & $9(18.7)$ & $14(40.0)$ & \\
\hline G3 & $16(33.3)$ & $3(8.6)$ & \\
\hline \multicolumn{4}{|l|}{ Unknown } \\
\hline Previous treatment & $1(2.1)$ & $6(17.1)$ & 0.047 \\
\hline None & $5(10.4)$ & $4(11.4)$ & \\
\hline Chemotherapy & $42(87.5)$ & $25(71.4)$ & \\
\hline \multicolumn{4}{|l|}{ Radio(chemo)therapy } \\
\hline Type of exenteration & $33(68.8)$ & $26(74.3)$ & 0.631 \\
\hline Anterior & $15(31.3)$ & $9(25.7)$ & \\
\hline \multicolumn{4}{|l|}{ Total } \\
\hline Resection Margins & $41(85.4)$ & $27(77.1)$ & 0.623 \\
\hline Microscopically negative (R0) & $6(12.5)$ & $7(20.0)$ & \\
\hline Microscopically positive (R1) & $1(2.1)$ & $1(2.9)$ & \\
\hline \multicolumn{4}{|l|}{ Grossly positive (R2) } \\
\hline Maximum tumor diameter, $\mathrm{mm}^{* *}$ & $35(2-50)$ & $35(1-120)$ & 0.273 \\
\hline Metastatic pelvic lymph nodes & $5(10.4)$ & $4(11.4)$ & 0.884 \\
\hline Adjuvant chemotherapy & $24(51.1)$ & $25(44.1)$ & 0.653 \\
\hline
\end{tabular}

Abstract 1088 Table 2 Peri-operative outcomes of MIPEs compared with open $\mathrm{PE}$

\begin{tabular}{|c|c|c|c|}
\hline Variable & $\begin{array}{l}\text { Open }(\%, \\
\text { range) }\end{array}$ & $\begin{array}{l}\text { MIPE (\%, } \\
\text { range) }\end{array}$ & $\begin{array}{l}\mathrm{p} \text { - } \\
\text { value }\end{array}$ \\
\hline Median Operative time, minutes (range) & $555(260-780)$ & $543(310-740)$ & 0.965 \\
\hline $\begin{array}{l}\text { Intra-operative median blood loss, } \mathrm{mL} \\
\text { (range) }\end{array}$ & $\begin{array}{l}800(150- \\
3000)\end{array}$ & $\begin{array}{l}500(200- \\
3500)\end{array}$ & 0.683 \\
\hline Intra-operative complications* & $10(20.8)$ & $3(8.6)$ & 0.220 \\
\hline $\begin{array}{l}\text { Major early ( } 30 \text {-day) post-operative } \\
\text { complications** }\end{array}$ & $9(18.8)$ & 0 & 0.009 \\
\hline $\begin{array}{l}\text { Median length of hospitalization, days } \\
\text { (range) }\end{array}$ & $17(7-110)$ & $10(6-73)$ & 0.156 \\
\hline
\end{tabular}

* All minor complications according to CTCAE 5.0

** Major (Grade $\geq 3$ ) according to Dindo et al.

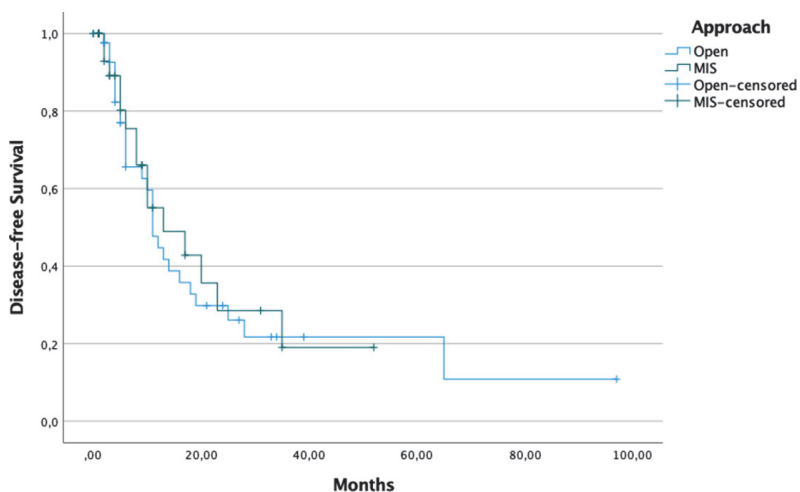

Abstract 1088 Figure 1 DFS comparison of MIS versus open PE.

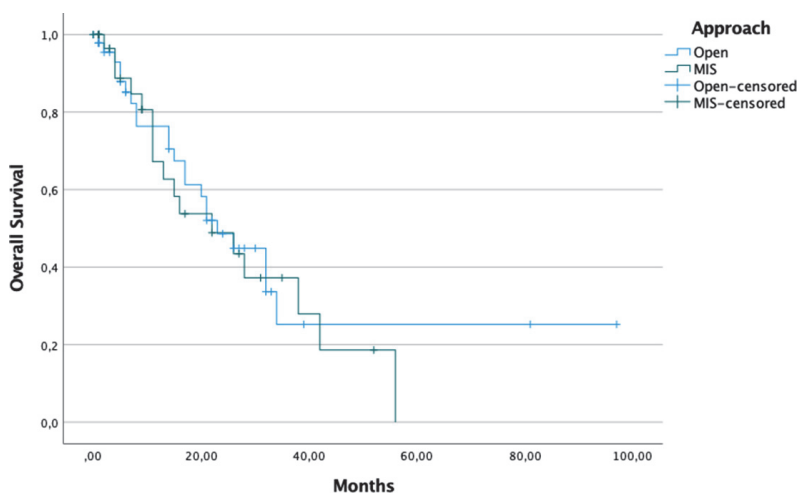

Abstract 1088 Figure 2 OS comparison of MIS versus open PE.

Conclusion* MIS for pelvic exenteration showed no DFS and OS difference when compared with OA, with lower rate of major early post-operative complications.

\section{CASE REPORT: 55-YEAR-OLD PATIENT WITH A FALLOPIAN TUBE WOLFFIAN TUMOR (FEMALE ADNEXAL TUMOR OF WOLFFIAN ORIRGIN)}

A Digeni* ${ }^{*}$ AA Avgoustidis, S Schiermeier. Marienhospital Witten, Gynecology and Obstetrics, Witten, Germany

\subsection{6/ijgc-2021-ESG0.289}

Introduction/Background* The Wolffian tumor is a rare, usually benign tumor first described in 1973 as a "female adnexal tumor of probable Wolffian origin (FATWO)". There have been less than 100 cases reported in the literature, with fewer than 30 cases of malignant or recurrent disease. ${ }^{1,2}$ These tumors are solid or cystic and characterised by small, closely packed cells like a 'sieve-like' patern. ${ }^{3-6}$ The majority of tumors occur within the broad ligament, fallopian tubes, mesosalpinx, or ovary. ${ }^{7}$ In the following report we describe the case of FATWO of the fallopian tube, discovered in a 55year-old female undergoing laparoscopic bilateral salpingooophorectomy.

Methodology A 55-year-old asymptomatic, postmenopausal patient was referred to our hospital with an adnexal mass for evaluation. Pelvic transvaginal ultrasound revealed a uterus myomatosus and a $8 \times 4 \mathrm{~cm}$ partially cystic, solid mass in the pouch of Douglas. The colour Doppler examination was negative. Serum tumor markers were negative (CEA, CA-125). The 


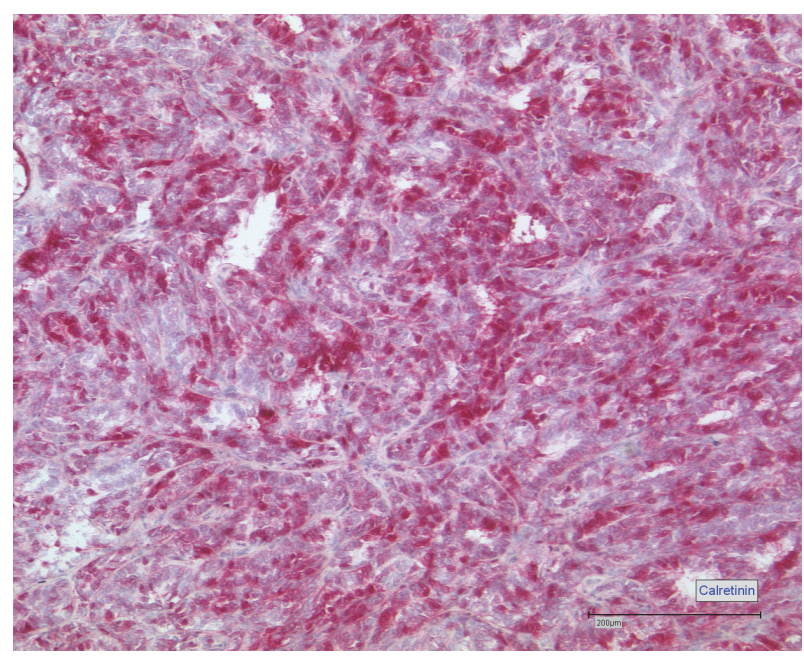

Abstract 1099 Figure 1

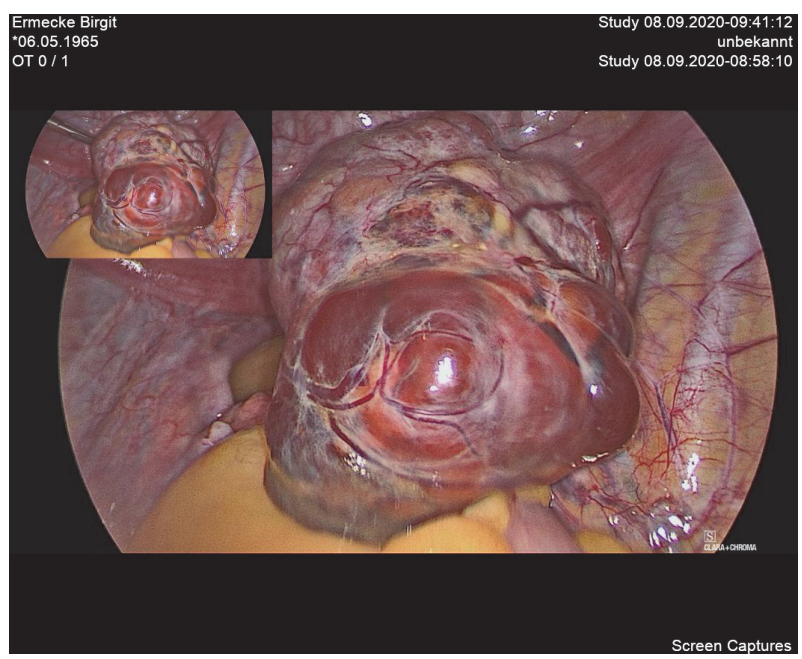

Abstract 1099 Figure 2

patient was prepared for a laparoscopic bilateral salpingooophorectomy which was successfully performed. Intraoperatively, an approx. $6.5 \times 4 \mathrm{~cm}$ twisted, round, solid-cystic structure with an irregular surface was discovered on the right fallopian tube. The mass was excised laparoscopically with both of adnexa using electrocautery. The postoperative phase was uneventful. The histology initially described an undifferentiated tumor which was shown by immunohistochemistry analysis to be a Wolffian tumor.

Result(s)* After negative staging with abdomen and thorax CT, the case was presented to the hospital's tumor board where treatments were discussed and a total laparoscopic hysterectomy was indicated. The patient underwent a total laparoscopic hysterectomy and abdominal biopsies with negative histology.

The rarity of the disease has led to poorly-defined therapeutic options. It has been considered that the most effective therapy is complete surgical resection with hysterectomy and bilateral adnexectomy. ${ }^{8,9}$ Sole tumor resection is a risk factor for relapse. The role of adjuvant chemotherapy or radiation is controversial. $^{8}$
Conclusion* Due to rarity of cases and data concerning the malignant progression of such tumors, more studies are required to decide upon the appropriate management. Although some cases are benign, there has been evidence of malignant behavior. The efficacy of adjuvant therapy is still in question. Following surgical treatment, regular follow-up examinations should be planned for the long-term.

\section{CARCINOSARCOMA OF THE FALLOPIAN TUBE: A CASE REPORT AND REVIEW OF THE LITERATURE}

${ }^{1}$ ME Capilna* , ${ }^{2} \mathrm{AL}$ Cozlea. "'George Emil Palade' University of Medicine, Pharmacy, Science and Technology, First Obstetrics and Gynecology Clinic, Târgu Mureş, Romania; ' 'George Emil Palade' University of Medicine, Pharmacy, Science and Technology, First Obstetrics and Gynecology Clinic, Târgu Mureş, Romania

\subsection{6/ijgc-2021-ESG0.290}

Introduction/Background* Carcinosarcoma, also known as Malignant Mixed Müllerian Tumor (MMMT), includes both malignant mesenchymal and epithelial elements. The fallopian tube is the most uncommon localization of this pathology, being associated with poor prognosis and an extremely aggressive progression.

Methodology A case of a 65-year-old postmenopausal patient with a final histological diagnosis of fallopian MMMT staged FIGO IC2, synchronous with a serous endometrial intraepithelial carcinoma, is described. From the literature, 99 previous case reports were reviewed. Gathered data was statistically analyzed together with the case from our clinic's experience,

Result(s)* Age between 41 and 60 years old, symptoms at presentation and CT/RMN tumor evidence could be prognosis factors $(\mathrm{P}<0.05)$. Omentectomy $(\mathrm{OR}=0.3545)$ and pelvic lymphadenectomy $(\mathrm{OR}=0.3732)$ are significant factors for survival $(\mathrm{P}<0.05)$. Fimbrial localization of tumor could be a negative prognosis factor ( $\mathrm{OR}=4.263)$, as well as heterologous type of tumor $(\mathrm{OR}=2.880)$. Chemotherapy improves survival $(\mathrm{OR}=0.2679)$ while radiotherapy has no influence on the prognosis.

Conclusion* Reporting this rare histology could be important to obtain more data regarding the optimal oncologic management, aiming to improve patients'survival.

\section{COMPLICATIONS RATES IN GYNECOLOGIC ONCOLOGY. A SINGLE CENTER EXPERIENCE}

DE Vlachos*, N Thomakos, V Pergialiotis, C Theofanakis, V Theodoulidis, D Haidopoulos, A Rodolakis. National and Kapodistrian University of Athens, 1st Department of Ob/Gyn, Athens, Greece

\subsection{6/ijgc-2021-ESG0.291}

Introduction/Background* Surgery in gynecological cancer remains one of the primary modalities of treatment. The procedures are now standardized and online video libraries are a source of knowledge and training for young surgeons. This accumulation of knowledge has promoted the surgical skills and increased the radicality of the procedures, especially in debulking surgeries that are now extended in upper abdomen or even the thoracic cavity. This increased radicality inevitable increases the complications during and after surgery. 